\title{
Glass transition effect of adhesive in timber beams strengthened with CFRP overlays
}

\author{
Rafat Krzywon ${ }^{1, *}$, Janusz Brol $^{1}$ \\ ${ }^{1}$ Silesian University of Technology, Department of Civil Engineering, Akademicka 5, 44-100 Gliwice, Poland
}

\begin{abstract}
There are situations when timber structure requires strengthening caused by environmental deterioration or changes in load conditions. Its mechanical performance can be increased by use of externally bonded high strength fibre reinforced composite (FRP). The place of application increases the sensitivity of this technique to environmental effects, including heating by the sun rays. Surface temperature can exceed $70{ }^{\circ} \mathrm{C}$, while usually as safe is considered $45^{\circ} \mathrm{C}$. Paper describes the tests of timber beams strengthened with two types of composites: unidirectional CFRP sheet and CFRP strip. They were heated at various temperature ranges and tested in bending. Out of the nine tested beams, only one heated to $95{ }^{\circ} \mathrm{C}$ was not damaged by the delamination of the composite overlay, remaining beams have not been destroyed due to achieved deflection exceeding the press cylinder range or were failed due to rupture of carbon fibres. The influence of the temperature was better recognizable in differences of deflections and strains caused by the creep in the adhesive layer weakened by temperature. It should also be emphasized that got results are much better than for commonly tested reinforced concrete beams, where delamination caused failure slightly above $65^{\circ} \mathrm{C}$.
\end{abstract}

\section{Introduction}

For hundreds of years, timber was the most popular construction material. From these times of supremacy, many valuable objects have survived to this day. Some of them require renovation, mainly because of natural processes of physical and biological degradation, but also because of climate changes, conditions of usage and increasing with them requirements of standards regarding actions and load coefficients. One of the most important rules of the Venice Charter [1] is to attempt to preserve the original substance of construction and materials. It limits the spectrum of available reinforcement and reconstruction techniques. Composites reinforced with high-strength fibres, thanks to their excellent mechanical properties, allow to increase the load bearing capacity with simultaneous non-noticeable interference in the geometry. This advantage, despite relatively high costs, promotes the popularization of this type of reinforcements in historically valuable objects. This is reflected in the growing number of applications in countries such an Italy or Greece, although there are also examples of applications in other countries, between them in Poland, where the strengthening of the Gliwice wooden Radio Tower is one of the best known $[2,3]$.

Although the idea of FRP composite reinforcement has been practically developed for over 30 years and many objects are regularly monitored since the strengthening time, there is still a too short period of time to judge the durability of such systems. Many potential problems have been recognized only in recent years. These include the glass transition temperature of polymers (mainly based on epoxy resins) used as a binder for high strength fibres.

The glass transition is a gradual process that begins for epoxies around $40 \div 50^{\circ} \mathrm{C}$ [4] and runs in the temperature range of $10 \div 20^{\circ} \mathrm{C}$ [5]. At this breadth of temperature, polymer softens by changing its amorphous solid state into a rubbery one. It provides to the deterioration of bond between FRP laminate and strengthened element. For that reason EBR FRP systems are not very resistant to elevated temperatures, they may behave poorly not only in a fire but also exposed to direct solar radiation. The phenomenon mentioned above is generally poorly recognized, especially there is the lack of laboratory tests of wooden samples. Currently expected behaviour of the strengthened timber structure at elevated temperature can generally be foreseen by analogy to concrete, for which actual tests are indicating the dangerous loss of the adhesive bond properties in the temperature between $60{ }^{\circ} \mathrm{C}$ and $70{ }^{\circ} \mathrm{C}[6]$. Temperature over $80^{\circ} \mathrm{C}$ leads to the total loss of bearing capacity of strengthening [7]. Creep of the weakened adhesive causes the increase of deflection [8]. It needs to be highlighted that irreversible creep strain in the adhesive provides to irreversible relaxation of stresses inside high strength fibres reinforcing the composite and thus a worsening of strengthening efficiency.

\footnotetext{
* Corresponding author: rafal.krzywon @ polsl.pl
} 


\section{Temperature increase caused by solar radiation}

Measures of temperature in the adhesive layer of CFRP laminate taken by the author of this paper during the summer months of 2015 have demonstrated the danger of heating above the temperature allowed by manufacturers of external strengthening systems. Details of that experiment and description of results can be found in $[9,10]$. Figure 1 shows timber prisms during the test.

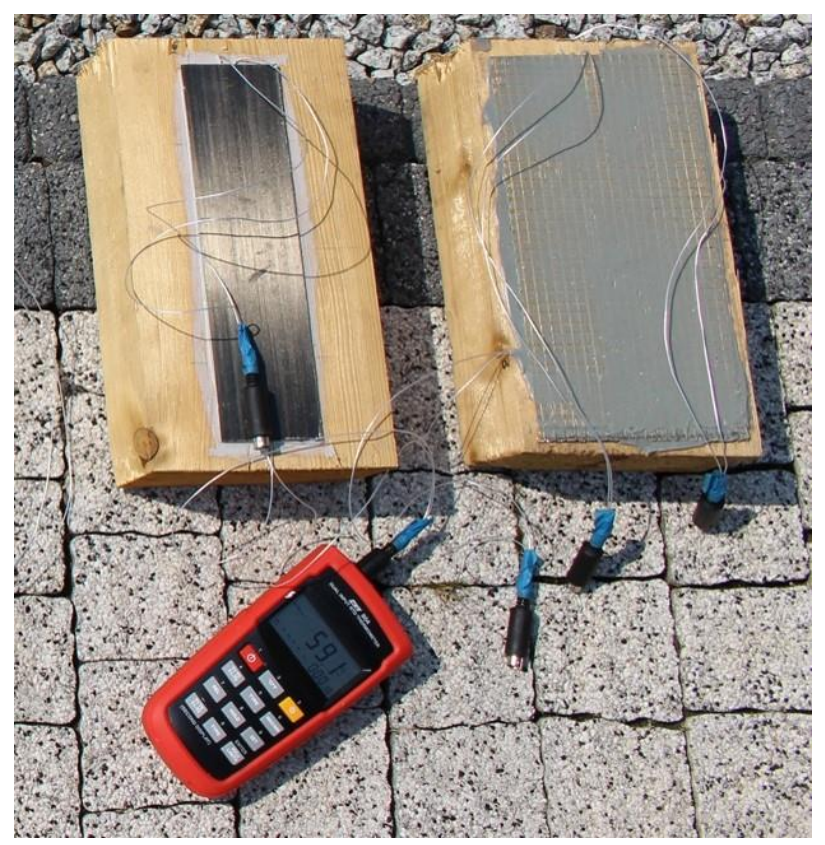

Fig. 1. Test of the influence of solar radiation o temperature.

Particularly interesting is the comparison of measures for wooden and concrete samples. Contrary to the original expectations (the wood itself in the sun heats up much less than the concrete), the adhesive layer in the wooden samples not only warmed up much faster but also reached much higher temperatures. The highest temperature measured for a wooden sample reached $72 \mathrm{C}$, while for a concrete sample, $64 \mathrm{C}$. This feature can be explained by the effect of the effect of thermal insulation. Wood, as a relatively good thermal insulator, does not absorb heat energy from the surface as effectively as concrete, thanks to which thin film of an adhesive and black CFRP laminate effectively accumulates this energy. 15-minute of solar exposure is required to achieve the adhesive temperature of $45^{\circ} \mathrm{C}$, while in concrete this same effect can be gained after almost 90 minutes. These results show a high risk related to the glass transition temperature achieved by composite reinforcement adhered to timber structures.

\section{Tests of beams under an elevated temperature condition}

\subsection{Research methodology}

The described research program has a preliminary character. An experimental program comprises nine timber beams, each of them tested in different conditions. Two types of strengthening material were used: CFRP S\&P Sheet 240 type $400 \mathrm{~g} / \mathrm{m}^{2}$ laminated as one layer with using $\mathrm{S} \& \mathrm{P}$ Resin 55 with thermal resistance declared to $80^{\circ} \mathrm{C}$ [11]; CFRP S\&P CFK $200 / 2000$ strip $60 \times 1.4 \mathrm{~mm}$ adhered with Sikadur $^{\circledR} 30$ adhesive having declared glass transition temperature of $52^{\circ} \mathrm{C}$ [12]. All beams were made of pinewood class $\mathrm{C} 27$. Beam designations and their features are described in Table 1.

The tests were carried out in four-point bending. The test stand is schematically presented in Figure 2. To intensify the strengthening effect and avoid the impact of torsional buckling beams have been bent towards the lower moment of inertia. Along the bottom surface, beams were heated using three linear infrared radiators. This method was chosen as the most similar to the operation of sun rays, where heating is caused by infrared radiation rather than convection. The most effective heating could be conducted after placing the heaters directly under the beam. However, this method creates the risk of damaging radiators by the delaminated composite overlay. Because of that, during the test heating was continued after moving radiators beyond the edge of the bottom surface what resulted in reduced efficiency of heating, but allowed to minimize the temperature drop during the test. In comparison to the
- strain gauge

- PT100 thermocouple

U1-U5 displacement transducer

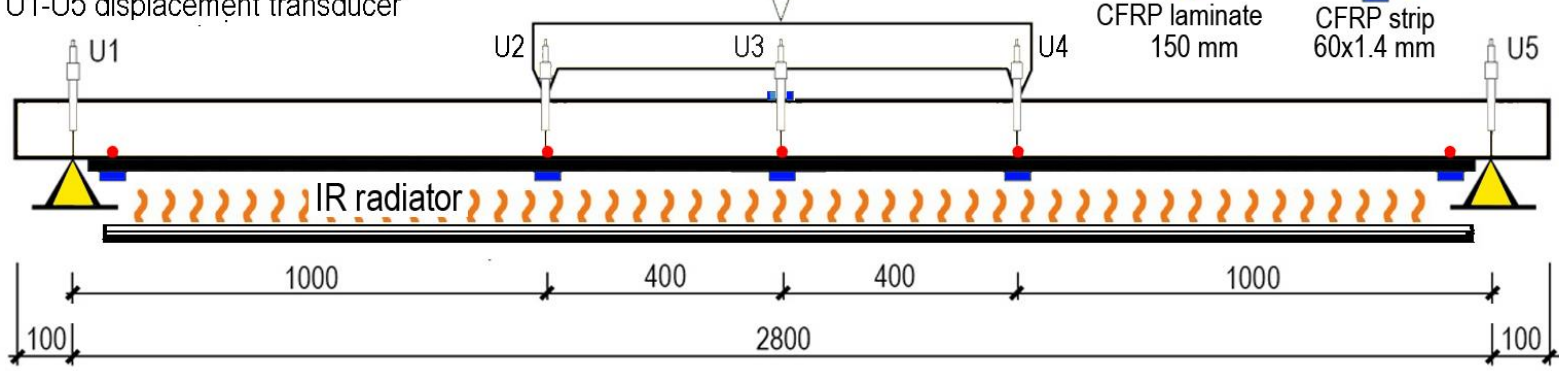

Fig. 2. Test layout. 
initial position of radiators, the temperature dropped by a maximum of $15^{\circ} \mathrm{C}$. Temperature changes for particular beams are described in Table 1.

The force was applied through a hydraulic press. All beams were loaded monotonically until the failure or range of the press piston. Force was controlled with dynamometer under the press. To determine deflections strains and the actual temperature of the adhesive layer beams were equipped with linear displacement transducers at five points along the length of the beam (support, force application points, the mid-span), strain gauges and PT100 thermocouples (Fig. 2).

Table 1. Features of tested beams.

\begin{tabular}{|c|c|c|c|c|}
\hline Beam symbol & Beam strengthening & Beam dimensions $[\mathrm{mm}]$ & $\begin{array}{c}\text { The maximum } \\
\text { temperature during } \\
\text { heating }\left[{ }^{\circ} \mathrm{C}\right]\end{array}$ & $\begin{array}{l}\text { Temperature change } \\
\text { during the test }\left[{ }^{\circ} \mathrm{C}\right]\end{array}$ \\
\hline $\mathrm{BB}$ & $\begin{array}{l}\text { Reference beam } \\
\text { (not strengthened) }\end{array}$ & $156 \times 76$ & 20 & 20 \\
\hline BCLT20 & \multirow{4}{*}{$\begin{array}{c}\text { one layer of CFRP } \\
\text { laminate } \\
\text { S\&P C Sheet } 240 \text { type } \\
400 \\
160 \mathrm{~mm}\end{array}$} & $158 \times 76$ & 20 & 20 \\
\hline BCLT50 & & $156 \times 77$ & 75 & $56 \rightarrow 42$ \\
\hline BCLT62 & & $159 \times 78$ & 89 & $65 \rightarrow 62$ \\
\hline BCLT62 & & $156 \times 77$ & 89 & $68 \rightarrow 64$ \\
\hline BCST20 & \multirow{4}{*}{$\begin{array}{c}\text { single CFRP strip } \\
\text { S\&P CFK 200/2000 } \\
60 \times 1.4 \mathrm{~mm}\end{array}$} & $158 \times 78$ & 19 & 19 \\
\hline BCST70 & & $159 \times 77$ & 72 & $70 \rightarrow 60$ \\
\hline BCST80 & & $158 \times 77$ & 80 & $80 \rightarrow 68$ \\
\hline BCST90 & & $158 \times 78$ & 89 & $88 \rightarrow 77$ \\
\hline
\end{tabular}

Table 2. Main test results.

\begin{tabular}{|c|c|c|c|c|}
\hline Beam symbol & Bearing capacity $[\mathrm{kN}]$ & $\begin{array}{l}\text { Deflection at failure } \\
{[\mathrm{mm}]}\end{array}$ & $\begin{array}{l}\text { Deflection at load } 10 \mathrm{kN} \\
{[\mathrm{mm}]}\end{array}$ & $\begin{array}{c}\text { Strain at load } 10 \mathrm{kN} \\
{[\mathrm{mm}]}\end{array}$ \\
\hline BB & 9.24 & 91,3 & - & - \\
\hline BCLT20 & 17.83 & 111 & 47.3 & 2.11 \\
\hline BCLT50 & 18.36 & 141 & 59.8 & 2.83 \\
\hline BCLT62 & $8.85 \mathrm{a}$ & $74,6^{\mathrm{a}}$ & - & - \\
\hline BCLT62 & 15.18 & 146 & 62.2 & 2.54 \\
\hline BCST20 & $-b$ & $>135^{b}$ & 51.4 & 2.10 \\
\hline BCST70 & $-b$ & $>140^{b}$ & 58.28 & 1.99 \\
\hline BCST80 & $-b$ & $>137^{b}$ & 55.8 & 1.98 \\
\hline BCST90 & 18.28 & 105 & 55.1 & 2.15 \\
\hline
\end{tabular}

a failure due to knock at mid-span,

${ }^{\mathrm{b}}$ beam has not been failed (achieved press cylinder range), test interrupted. 


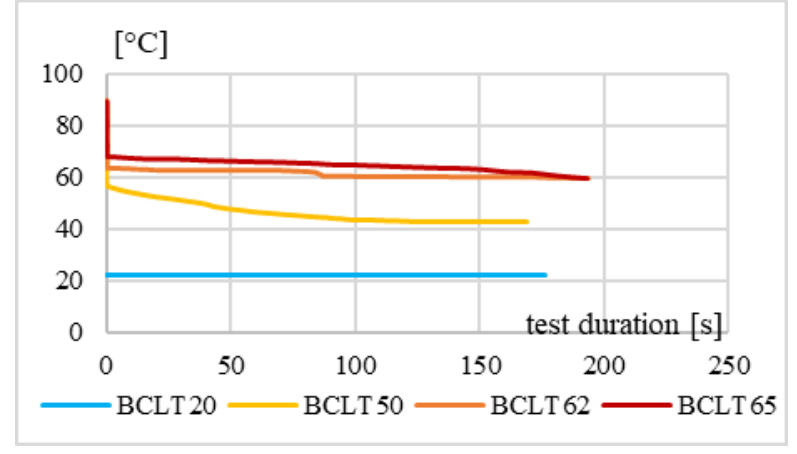

Fig. 3. Temperature change during the test of BCLT beams.

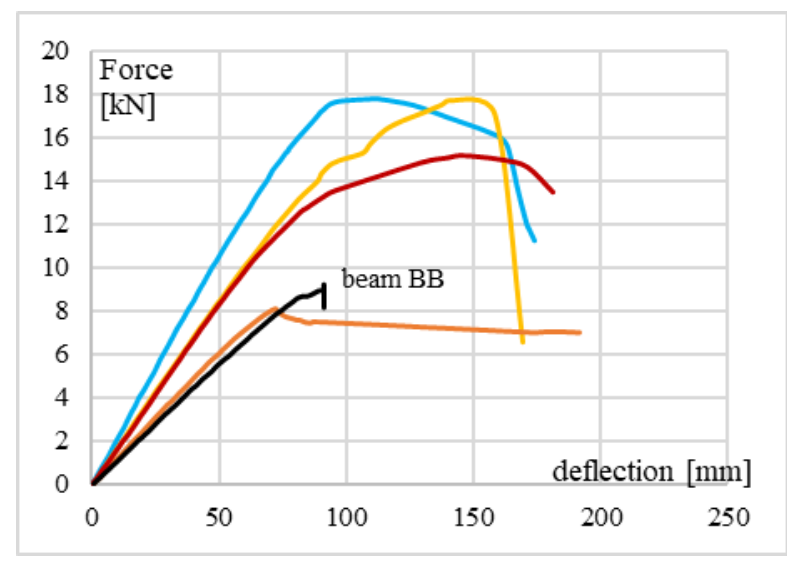

Fig. 4. Deflection of BCLT beams.

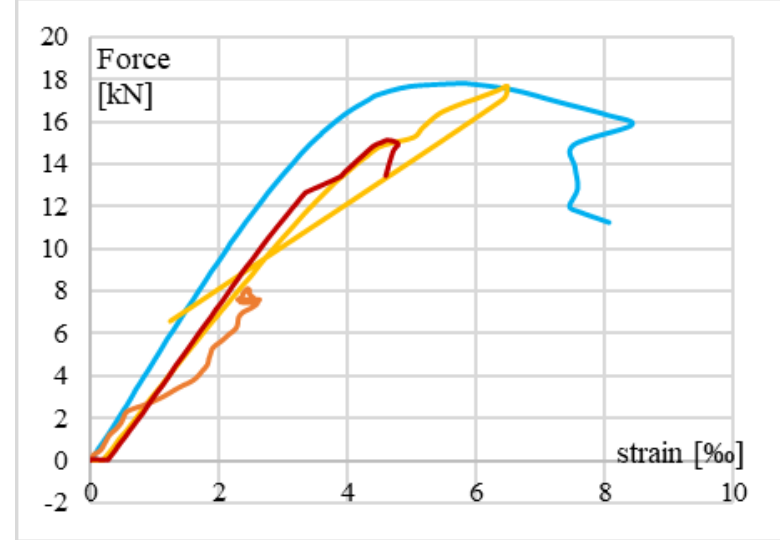

Fig. 5. Mid-span strains of composite for BCLT beams.

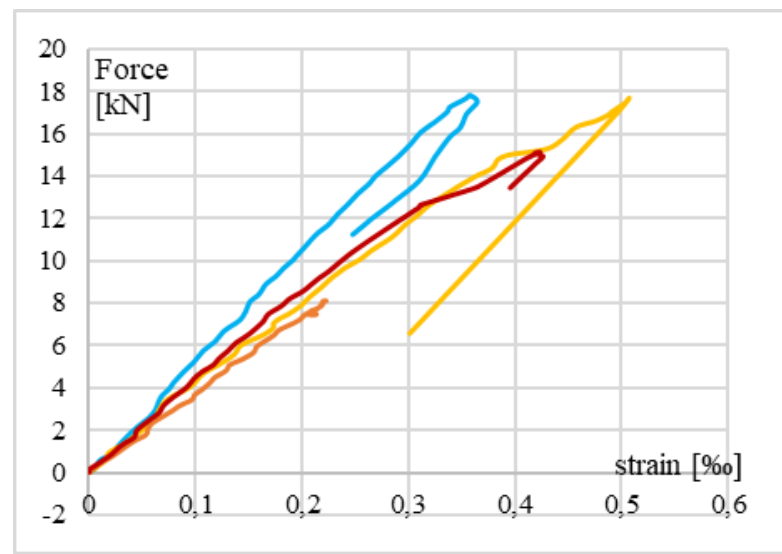

Fig. 6. Anchorage strains of composite for BCLT beams.

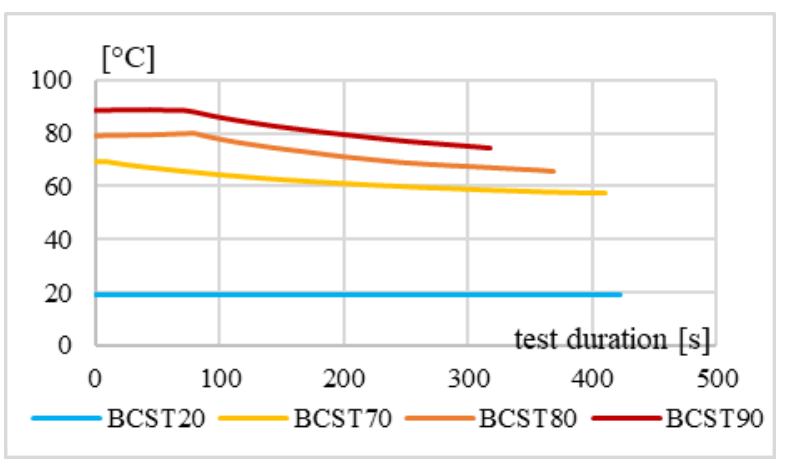

Fig. 7. Temperature change during the test of BCST beams.

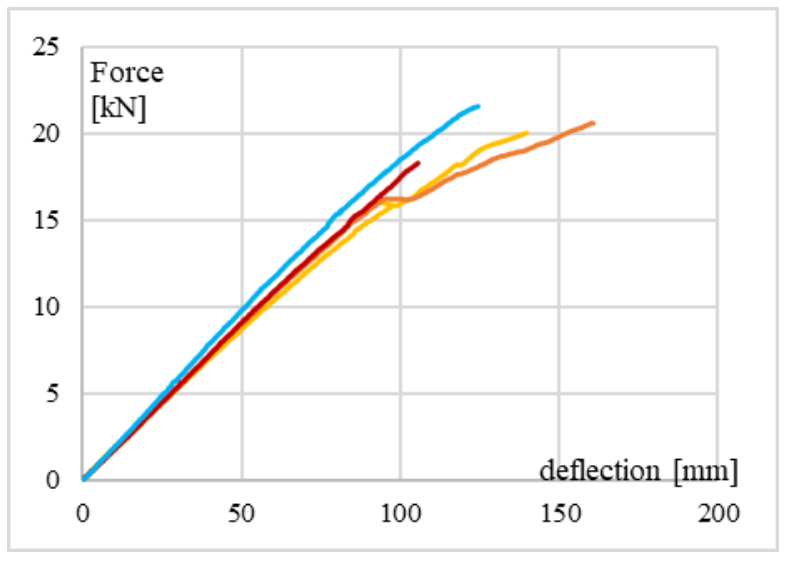

Fig. 8. Deflection of BCST beams.

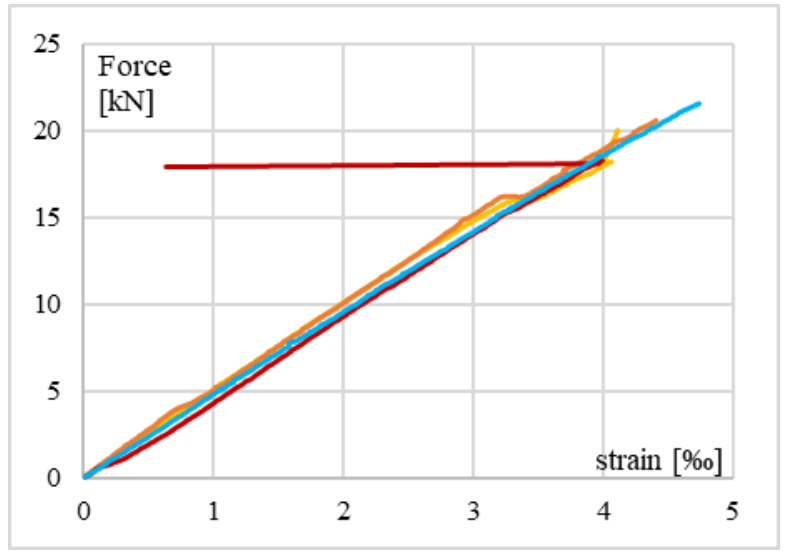

Fig. 9. Mid-span strains of composite for BCST beams.

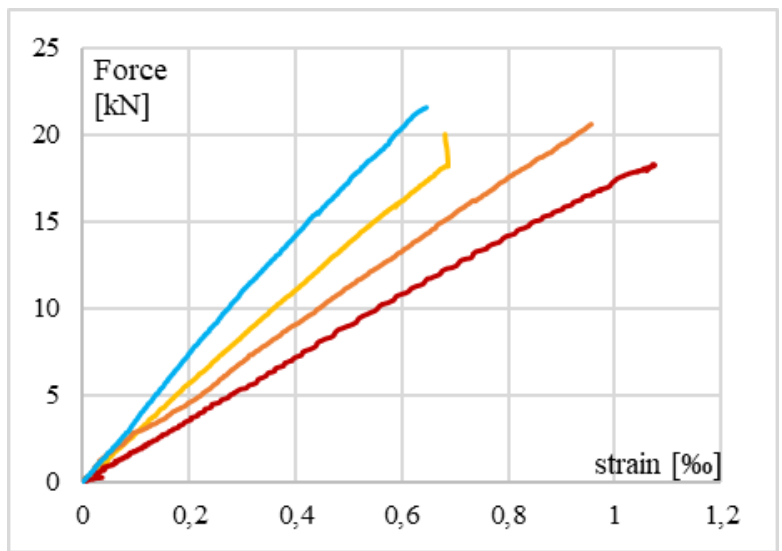

Fig. 10. Anchorage strains of composite for BCST beams. 


\subsection{Test results}

The primary objective of the research was to determine the effect of the adhesive temperature on the strengthening effectiveness expressed by the bearing capacity and deflection. Also, in the case of beams reinforced with CFRP strip, creep in the adhesive was measured as a difference between the strain of composite overlay and adjacent timber surface.

Selected test results are presented in Table 2. The diagrams in Figures $3 \div 6$ and $7 \div 10$ show the temperature change, change in deflection, increase of the strain of composite overlay in the mid-span zone and the support zone. Figure 11 shows the difference between deformation of the carbon strip and adjacent timber surface in the anchorage zone. Results are presented separately for BCLT and BCST models because of differences in geometry of laminate and strips.

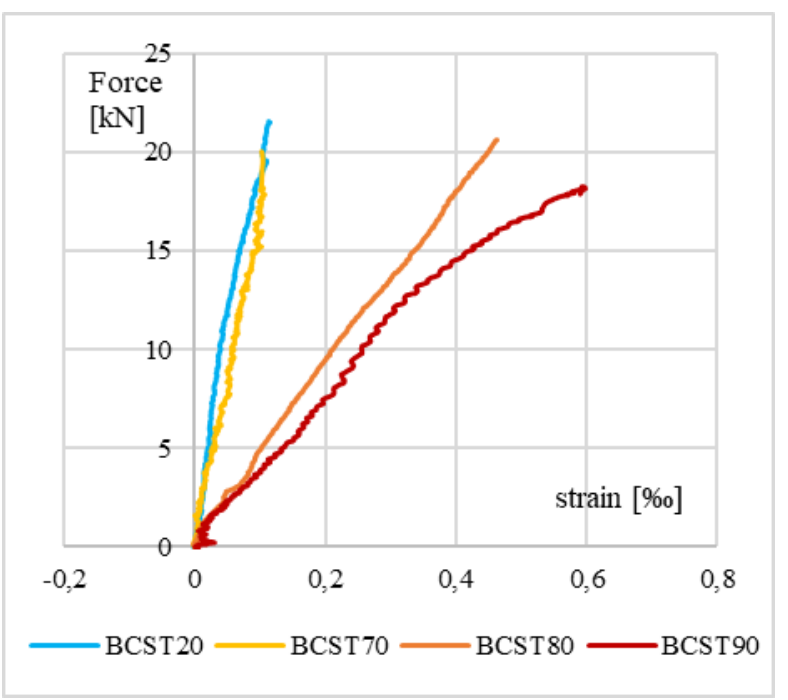

Fig. 11. Difference between anchorage strains of composite and adjacent timber surface for BCST beams.

\section{Discussion of the test results}

\subsection{Load-bearing capacity}

Two models of damage were observed in the beams strengthened by lamination of CFRP sheet: the compressive crushing of wood fibres (BCLT20 and BCLT65) and rupture of carbon fibres (BCLT50 and BCLT62, Fig. 12). There was no delamination of composite overlays in any of the tests. The load-bearing capacity of the BCLT50 beam was even slightly higher than BCLT22 beam tested at room temperature. This can be explained by the effect of accelerated ageing in medium temperatures reported by other researchers $[13 \div 15]$. As expected, the decrease in the load capacity can already be noticed above $60 \mathrm{C}$, although the lowest load capacity of the BCLT62 cannot be considered trustworthy, because the destruction occurred as a result of the wood defect having the form of a knot in the zone of the maximum bending moment. It caused a transverse deformation that cut through the CFRP fragile laminate.
Surprising was the study of beams reinforced with carbon tape. Despite the low, declared by producer glass transition temperature for Sikadur ${ }^{\circledR} 30$ adhesive, only one beam was broken during the test. That was the BCST90 beam tested at the highest temperature of about $90^{\circ} \mathrm{C}$. The observed form of its destruction was already in line with expectations. It was delamination of the contact layer of epoxy adhesive and CFRP tape (Fig. 13). This mechanism confirms the effect of elevated temperature on mechanical properties (adhesion) of the epoxy used, albeit in a relatively high temperature. The other beams in the BCST group were not destroyed due to the limitations of the testing device. As a result of the deflection of beams, the press piston reached its final position, which did not allow further application of force.

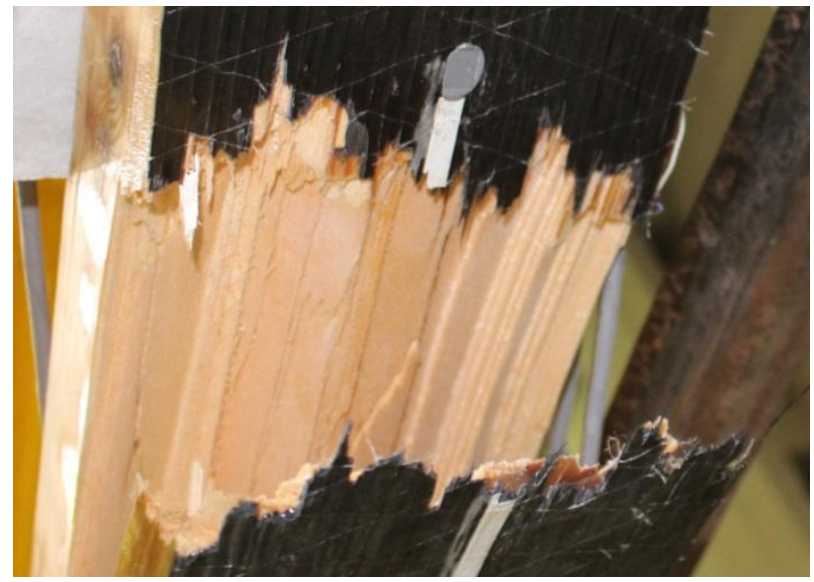

Fig. 12. Rupture of carbon fibres of BCLT50 beam.

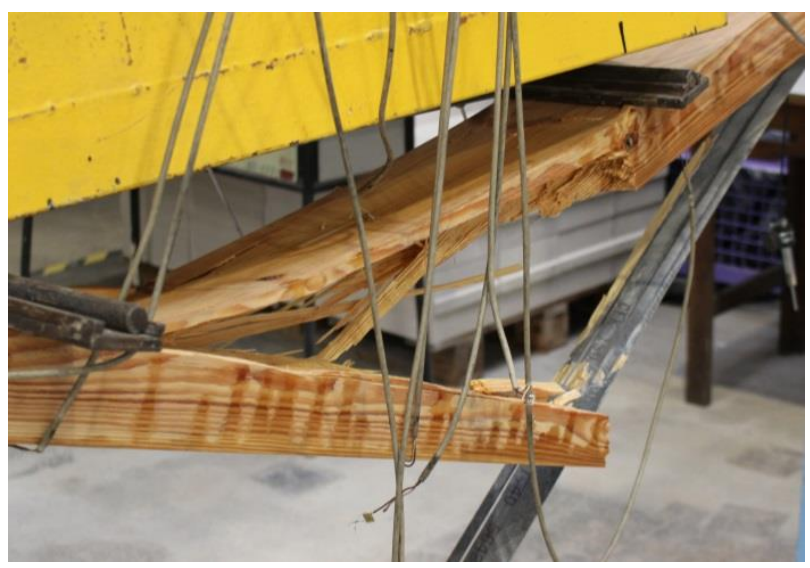

Fig. 13. Delamination failure of BCST90 beam.

\subsection{Deflections}

For all tested beams, there was a tendency for greater deformability at higher temperatures. This effect can be demonstrated by observations at the same load level (Table 2). At $10 \mathrm{kN}$, the deflection of BCLT50 beam is $26 \%$ higher than BCLT22, whereas the deflection of BCLT65 beam is higher by $31 \%$.

Measurements obtained for BCST beams are not so evident, but still noticeable. The largest deflection was achieved for BCST70 beam and was 13\% higher than 
deflection of the reference beam. Deflections of BCST80 and BCST90 beams were similar and higher by $8 \%$ than BCST20.

The increased deflection means a decrease in stiffness. The softening of the adhesive at the glass transition temperature causes a deterioration of the bond with the strengthening overlay because of creep in the adhesive layer, and as a result, the lower stiffness of the cross-section.

\subsection{Strains}

The increase in curvature caused by the temperature is also reflected by the differences in deformations of the CFRP overlays. This influence is noticeable for the BCLT models in both the span zone and the anchorage (Fig. 5, Fig. 6). For BCST beams, the mid-span strains are similar, regardless of the temperature (Fig. 9), but considering the composite thickness effect, it can be concluded that at the elevated temperature they are lower. Strains for these models are increasing towards the supports. In the anchorage zone itself, the composite strip strains of the BCST90 beam are already about twice as high as for the beam tested at room temperature (Fig. 10). This can be explained by the influence of slip in the adhesive layer, between the wood surface and the composite overlay, and the transfer of increasing deformation towards the anchorage zones. It is also proved by comparison of strains of the CFRP strip and the adjacent wood surface (Fig. 11). At room temperature, the slight difference is caused by the thickness of the composite overlay. At the temperature above $70^{\circ} \mathrm{C}$, that difference is visibly greater.

\section{Conclusions}

Got test results show that at the temperature of about $50 \div 60{ }^{\circ} \mathrm{C}$, the first symptoms of the weakening of the adhesive bonding the composite to the wood surface appear. Proof of that phenomenon is the increasing deformability, but it could also be noticeable under the touch of a finger, as softening of the laminate.

In contrast to reinforced concrete beams strengthened with carbon strips [16], the softening of the adhesive does not significantly affect the reduction of bearing capacity of timber beams. It is a beneficial property, and most probably it should be associated with lack of cracking characteristic for the concrete surface, which significantly detaches the lengths of effective anchoring. The smooth surface of the strained wood increases the temperature, which can be considered as dangerous for the bearing capacity above $70{ }^{\circ} \mathrm{C}$.

A separate phenomenon is an increase of deformability confirmed during the tests. Under normal conditions, the adhesive bond is stiff [17]. The rise in temperature and the creep of the adhesive may lead to relaxation of the strips and deterioration of the strengthening efficiency.

Paper was created as a part of the implementation of the $\mathrm{z}$ BK235/RB6/2017 project at the Department of Structural Engineering of Silesian University of Technology. Authors wish to acknowledge for the received financing from the University.

\section{References}

1. International Charter for the Conservation and Restoration of Monuments and Sites (The Venice Charter 1964), ICOMOS (1965)

2. A. Ajdukiewicz, A. Malczyk, M. Właszczuk, J. Brol, Wiadomości Konserwatorskie, 14, 28, (2003)

3. A. Ajdukiewicz, Structure Engineering International, 10 (3), 161 (2000)

4. J. Michels, R. Widmann, C. Czaderski, R. Allahvirdizadeh, M. Motavalli, Composites Part B, 77, 484 (2015)

5. G. Hülder, C. Dallner, G.W. Ehrenstein, Bauingenieur, 81, 449 (2006)

6. R. Krzywon, "Behaviour of EBR FRP strengthened beams exposed to elevated temperature,", Procedia Engineering, Vol. 193, pp. 297-304, 2017.

7. J.B. Aguiar, R. Krzywon, A. Camoes, M. Górski, S. Dawczyński, Proceedings: 8th International Symposium on Utilization of High-Strength and High-Performance Concrete, 239 (2008)

8. T. Ulaga, U. Meier, Proceedings of the FRPRCS-5 Conference, 147, (2001)

9. R. Krzywoń, Materiały Budowlane, 5, 10 (2017)

10. R. Krzywoń, ACEE Architecture Civil Engineering Environment, 9 (1), 79 (2016)

11. S\&P Resin55 technical datasheet, (http://www.sppolska.pl/assets/files/pf3_resin_55_09.12, access 28.08.2016).

12. Sika Sikadur-30, Thixotropic epoxy adhesive for bonding reinforcement, product data sheet, (https://pol.sika.com/dms/getdocument.get/e4fc345c -84e7-35ad-a672-5616e67f829e/KT\%20Sikadur-, access 28.01.2018)

13. O. Moussa, A.P. Vassilopoulos, J.D. Castro, T. Keller, Journal of Applied Polymer Science, 127(4), 2490 (2013)

14. D. Othman, T. J. Stratford, L. A Bisby, Proceedings of the FRPRCS11, UM, Guimaraes (2013)

15. R.J.C. Carbas, E.A.S. Marques, A.M. Lopes, L.F.M. da Silva, Proceedings of the 15th International Conference on Experimental Mechanics ICEM2015, University of Porto (2012)

16. R. Krzywoń, Czasopismo Inżynierii Lądowej, Środowiska i Architektury, 64(3/I), 271, (2017)

17. J. Brol, Zeszyty Naukowe Politechniki Śląskiej, Budownictwo, 93, 67 (2001) 